\title{
EXPERIMENTAL, NUMERICAL AND ANALYTICAL INVESTIGATIONS OF WIND-INDUCED NET PRESSURES FOR INDUSTRIAL BUILDINGS WITH ENVELOPE POROSITIES
}

\author{
VAnessa SAubKE*, RÜDIger HÖFFeR
}

\author{
Ruhr-Universität Bochum, Universitätsstraße 150, 44801 Bochum, Germany \\ * corresponding author: vanessa.saubke@rub.de
}

\begin{abstract}
The magnitude and the spatial distribution of wind-induced net pressures (external and internal) on buildings are frequently discussed among research communities and construction industries. This paper deals with this topic based on a case study about an industrial building in Denmark, which was damaged due to the wind impact during a storm when a large part of the roof covering was blown off. In order to detect the reason for the damage the wind-induced loads were studied by i) wind tunnel experiments on the external pressures due to different wind directions, ii) analytical investigations of internal pressure due to envelope porosities and planned openings and iii) numerical analyses for the internal and the external pressure. The Reynolds averaged Navier-Stokes (RANS) method is employed to build a numerical model. The experimental, analytical and numerical results are compared with the indicated characteristic loads from the Eurocode [1].
\end{abstract}

KEYWORDS: net pressure, internal pressure, industrial building, Eurocode.

\section{INTRODUCTION}

The storm "Christian" caused a lot of significant damages in Northern Europe in October 2013, including also failure of supporting structures of buildings. Especially in Denmark high wind velocities were measured. According to the Danish meteorological service local wind peaks of $53.5 \mathrm{~m} / \mathrm{s}$ were listed, which were the highest values ever measured in Denmark. The wind velocity distribution for the maximum values for this day is given in Figure 1 (b). The diagram in Figure 1 (c) shows the data of the two measurement stations nearby the building which is considered here. The peaks of the wind velocity at 1 p.m. and at 3 p.m. are clearly visible.

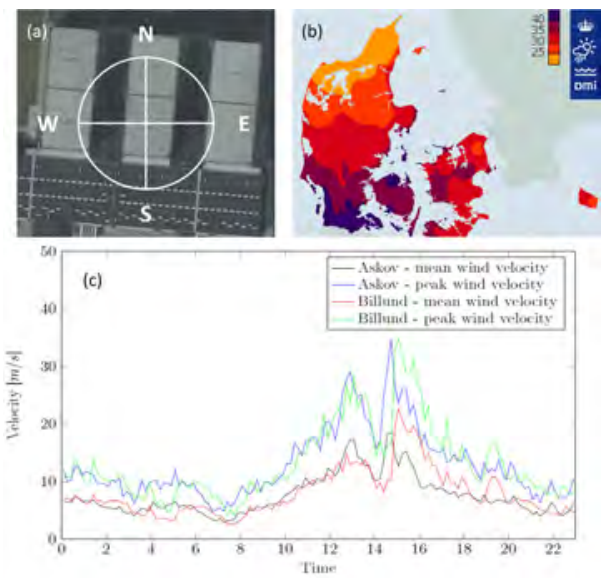

Figure 1. (a) Cardinal points (Google Earth [2], modified), (b) distribution of the peak wind velocity in Denmark during hurricane "Christian" in October 2013 (Danmark Meteorologiske Institut [3], modified) and (c) measurements of the wind velocities at stations near to the building.
At 3.15 p.m. the industrial building was damaged due to the wind impact. A large part of the roof structure breaks off and leads to an extended hole in the roof construction (see Fig. 3 (a)). The debris were blown over the building and damaged also the leeward building (see Fig. 2). The wind direction was west-southwest (for the cardinal points see Fig. 1 (a)).

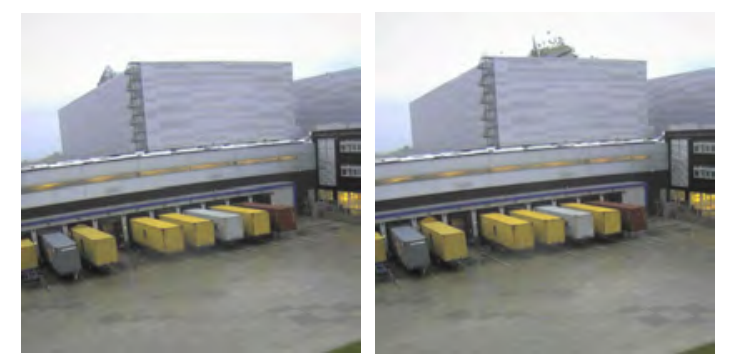

Figure 2. Pictures from a security camera taken during the storm in 2013, the roof failure is visible.

The damage started at the edge of the roof where the foil peeled off. This led to a deformation of the parapet wall (see Fig. 3 (d)). Approximately 7.5 $\%$ of the roof construction was completely blown off, additional $6 \%$ of the roof foil was torn off and the trapezoidal sheets were folded and buckled (see Fig. 3 (b)). In total more than $10 \%$ of the roof construction was destroyed. Futhermore this caused a damage at the sprinkler system and the leaking water destroyed a big part of the stored goods. The impact of the wind load was huge so that also the girders of the supporting roof construction were deformed (see Fig. $3(\mathrm{c}))$. 

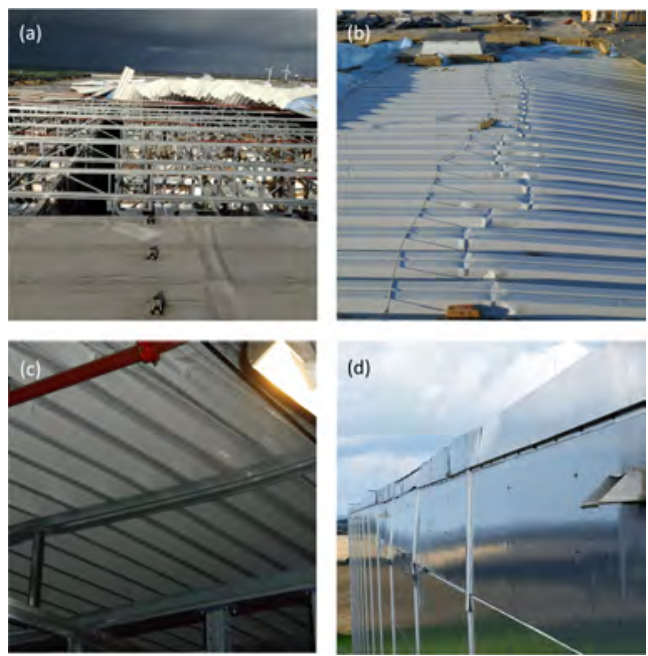

Figure 3. Qualitative description of typical damages: (a) Partically opened roof, (b) buckled sheets, (c) bent girder and $(\mathrm{d})$ deformed parapet.

The considered building is located in the east part of Denmark. It is situated at the west of a complex of three storage buildings of the same type. Each building is about $135 \mathrm{~m}$ long, $55 \mathrm{~m}$ wide and 38 $\mathrm{m}$ tall. The shelfs for the stored goods are part of the supporting steel construction which consists of a regular framework of stiffening frames (see Fig. 4). This main structure is covered by a sandwich-element facade.

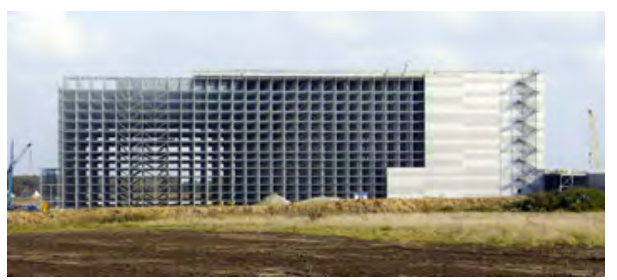

FiguRE 4. Example of a warehouse building under construction (Google Maps [2]).

The roof consists of supporting girders, trapezoidal sheets, mineral insulating panels and a roof foil. The sheets are connected to the supporting girders by screws and the foil is fixed by spikes. For the sandwichelement facade a connection type with unsealed joints was used. After Lange and Rädel [4] this specific joint construction can lead to a leakage of the building walls. For the consideration of this leakage an effective joint was estimated as $3.5 \mathrm{~mm}$ (for investigations on the leakage of joint see Kuhnhenne [5]). With this information the general porosity $\phi$, the relation of the area of the openings to the area of the surfaces, was calculated:

$$
\phi=\frac{\sum A^{\prime}}{\sum A}=0.0026=0.26 \% .
$$

At the southern facade the gates for the delivery of the goods are located behind an antecedent flat hall. If the gates are not closed the total area of openings is $61.43 \mathrm{~m}^{2}$.

\section{Materials and Methods}

\subsection{Wind LOADS AFTER 1991-1-4}

After the Eurocode external and internal pressures due to wind impact are taken into account [1. A superposition of both leads to the net pressure. The definition of the signs of this values are given in Figure 5.

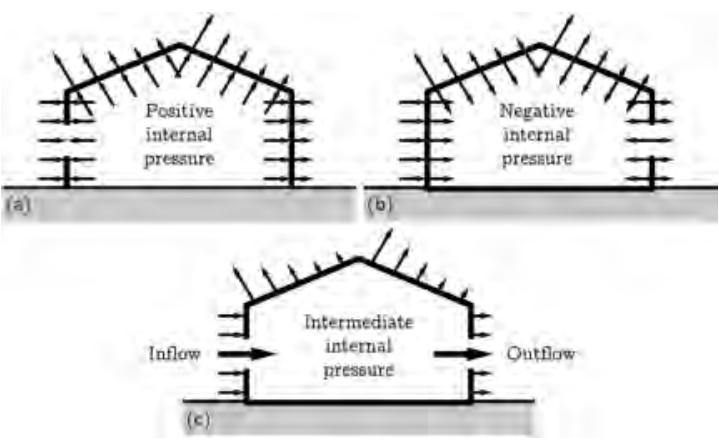

Figure 5. Three typical cases for the internal pressure (Cook 6, modified).

The code defines the wind load $w_{e, i}$ as multiplication of the peak velocity pressure and a pressure coefficient:

$$
w_{e}=q_{p} \cdot c_{p e} \quad \text { and } \quad w_{i}=q_{p} \cdot c_{p i} .
$$

The peak velocity pressure $q_{p}$ is influenced by different factors like the terrain category, the building height and the wind zone. The external pressure coefficient $c_{p e}$ is influenced by the shape of a building and the internal pressure coefficient $c_{p i}$ by the distribution of the openings over the four faces of the building. In the following investigations pressure coefficients are considered and compared. For this purpose the external pressure coefficients for the roof of this building are determined in Table 2

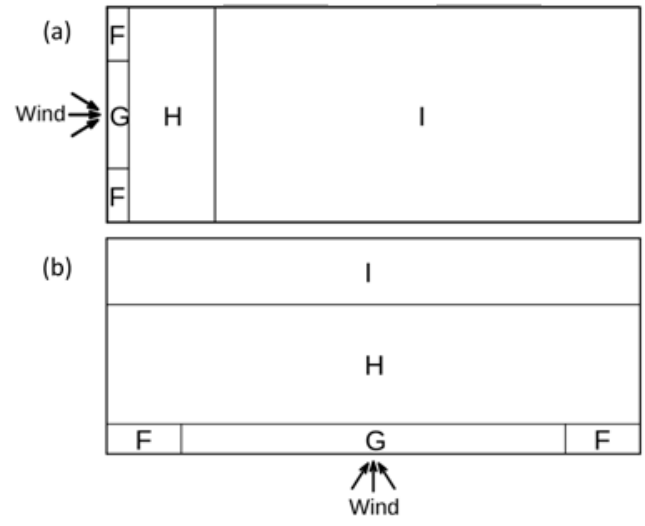

FiguRE 6. Distribution of the pressure coefficients for a flat roof with (a) wind direction on the short side and (b) wind direction on the long side.

Regarding the flow around a rectangular cube of a certain height (see Hucho [7]) the code estimation of 
the distribution of the pressure coefficients is given in Figure 6 The distribution depends on the dimensions of the building and has to be estimated for every building and every wind direction individually due to the regulations. The $c_{p e, 1}$ values should be used for loaded areas of less than $1 \mathrm{~m}^{2}$ and the $c_{p e, 10}$ values for loaded areas of more than $10 \mathrm{~m}^{2}$ with the possibility of a logarithmic interpolatin for intermediate values. The internal pressure can be calculated according to two different regulations:

(1.) For homogeneously distributed openings the pressure coefficient can be determined from a diagram by calculating the opening ratio $\mu$, which is the relation from the area of the openings in the suction region divided by the area of all openings:

$$
\mu=\frac{\sum \text { area of openings with } c_{p e} \leq 0}{\sum \text { area of all openings }}
$$

(2.) A Face with an area of openings that is more than twice the area of the sum of the openings in the remaining faces is considerd as a dominant face.

- The internal pressure coefficient can be calculated with the following equation:

$$
c_{p i}=0.75 \cdot c_{p e}
$$

- If the area is more than three times the remaining openings then it is calculated with the following equation:

$$
c_{p i}=0.9 \cdot c_{p e} .
$$

The considered building has firstly a general porosity because of the leakage due to the facade-elements. Secondly it has large openings for the delivery of the stored goods at the short face where the open flat building is located. It is not known yet if openings were open or closed during the storm. Therefore, three different situations for two wind directions are considered. These different cases are explained in Table 1 .

\begin{tabular}{|c|c|c|c|}
\hline Case & Windward Face & Porosity & Delivery Gates \\
\hline 1 & \multirow{3}{*}{ short } & $\mathrm{X}$ & \\
\hline 2 & & $\mathrm{X}$ & $\mathrm{X}$ \\
\hline 3 & & & $\mathrm{X}$ \\
\hline 4 & \multirow{3}{*}{ long } & $\mathrm{X}$ & \\
\hline 5 & & $\mathrm{X}$ & $\mathrm{X}$ \\
\hline 6 & & & $\mathrm{X}$ \\
\hline
\end{tabular}
The results for the internal pressure coefficients for these six cases are listed in the Table 3 .

TABle 1. Description of the six load cases.

\subsection{EXPERIMENTAL TESTS}

Wind tunnel tests were performed at the Boundary Layer Wind Tunnel at Ruhr-Universität Bochum to build up a reference data-base of wind-induced loads on the structure for specifically chosen spots of the building envelope, especially on the parts damaged during the storm event. The focus of the measurements was set on the roof construction which failed (see Fig. $7(\mathrm{a})$ ). The effect of the parapet wall was neglected due to the small size in relation to the building. This leads to results on the safe side.

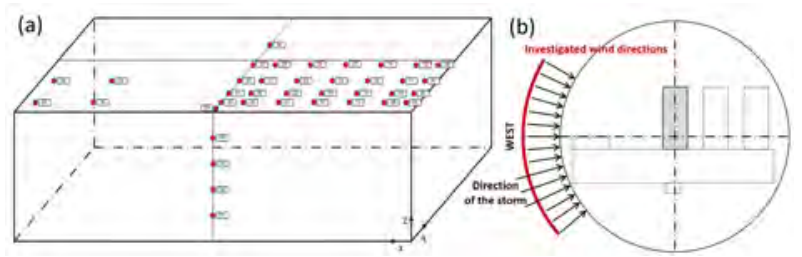

Figure 7. (a) Positions of the pressure measurement points and (b) the principal set-up of the model.

The tests were performed in a geometrical scale of 1:300 for different wind directions from southwest to northwest. The building was investigated as a (i) single standing, isolated building and (ii) in a group arrangement with the neighboring buildings (see Fig. 7 (b) for the set-up). The evaluated $c_{p e}$ values represent the $78 \%$ fractiles of the analyzed measurement data. The pressures are measured over a point-like averaging area which represents an area smaller than $1 \mathrm{~m}^{2}$ in full scale.

The minimum values from the flow direction on the long face and of all measured directions for every zone are listed in Table 2

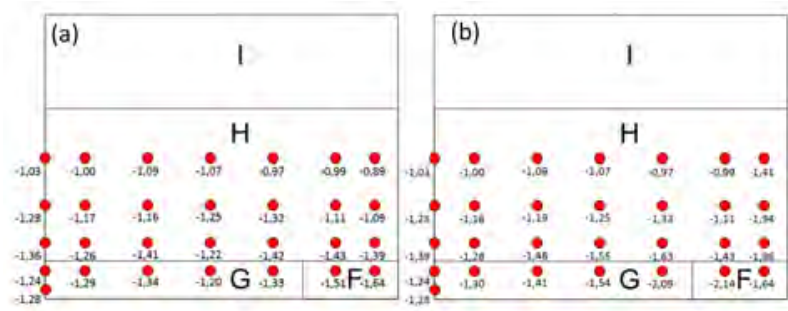

Figure 8. (a) The minimal $c_{p e}$ values of the flow direction west (on long face) and (b) of all measured flow directions.

\subsection{NUMERICAL SIMULATIONS}

For the numerical investigations a CFD method applying finite volumes and the RANS method with the standard $\mathrm{k}-\epsilon$-model is used. The applied inlet velocity profile was introduced by Richards and Hoxey [8] in 1993 and is commonly used for this method. Effects of building interferences were neglected by running all simulations with a single building.

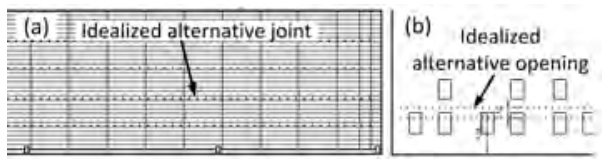

Figure 9. (a) Idealization of the joints and (b) idealization of the openings. 
Because a simulation of all explicit openings and joints would lead to an extremely high number of volume elements the openings were idealized. The general porosity of the joints was considered with four explicit idealized joints distributed over the height (see Fig. 9, left). The openings of the delivery gates were also idealized as one large opening with the same area which is located in the center of gravity of all gates (see Fig. 9] right).

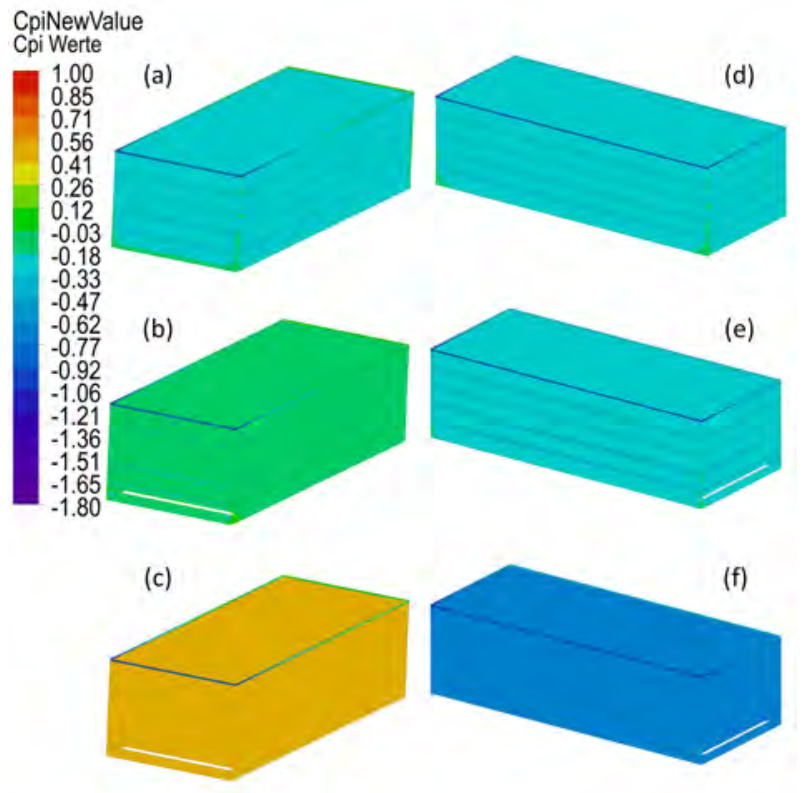

FIgURE 10. Numerical results for the internal pressure coefficients $c_{p i}$ : (a) case 1 , (b) case 2 , (c) case 3 , (d) case $4,(\mathrm{e})$ case 5 and (f) case 6.

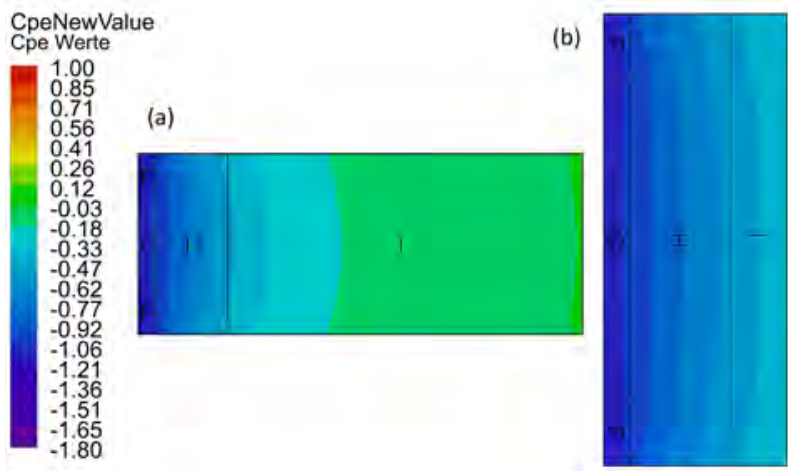

FiguRE 11. Numerical results of the external pressure coefficients of the roof for (a) flow on the short side and (b) flow on the long side.

Geometrical models and meshes were generated for all six cases (see Table 1) with approximately three million volume elements per case. The distribution of the external pressure coefficients is pictured in Figure 11. The maximum values for every zone are listed in Table 2 The internal pressure coefficients for the six different cases are plotted in Figure 10 and numbered in Table 3

\subsection{Analytical Calculations}

An analytical investigation is performed for the estimation of the internal pressure. As Cook [6] 1990 already described, the internal pressure $p_{i}$ depends on the external pressure $p_{e}$ at the openings $A^{\prime}$. It is defined as the balance between the inflow and outflow of the building (see also Fig. 5 (c)):

$$
\sum^{\text {inflow }}\left(A^{\prime}\left(p_{e}-p_{i}\right)^{\frac{1}{2}}\right)=\sum^{\text {outflow }}\left(A^{\prime}\left(p_{i}-p_{e}\right)^{\frac{1}{2}}\right) .
$$

The equation cannot be solved directly but iteratively with an estimated value for the internal pressure. The left-hand and right-hand side of Equation 6 are not fixed during the iteration process, because an outflow can become an inflow and vice versa.

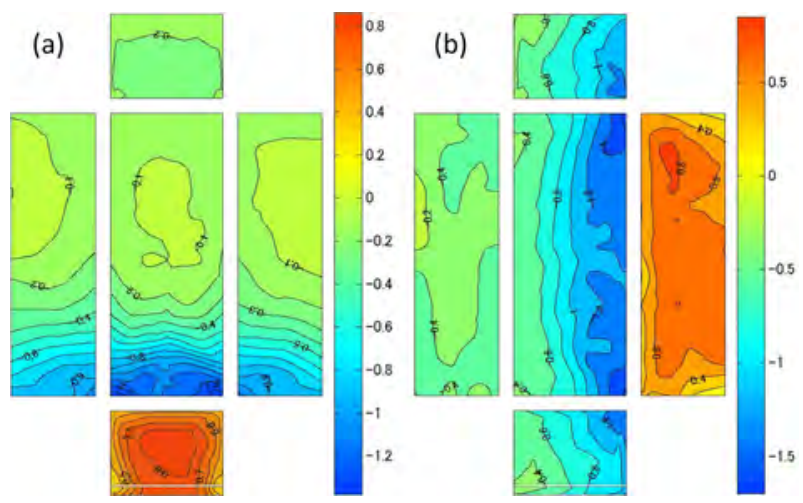

FiguRE 12. Distribution of the external pressure coefficients from a wind tunnel test for (a) the wind direction on the short face and (b) the wind direction on the long face (TPU Aerodynamic Database [9, modified).

To calculate the internal pressure analytically a distribution of the external pressure is needed. Because the performed wind tunnel tests are putting the focus on the damaged area of the roof construction, complete roof and wall distributions of external pressures have not been measured and are missing for analytical calculations of internal pressures. Therefore mean values of external pressure coefficients from wind tunnel tests of a building with similar proportional dimensions from the TPU Aerodynamic Database [9] were used (see Fig. 12. Because the building from the database was smaller than the original one, the area of the openings was scaled down whereas the opening ratio $\mu$ stayed unchanged. In this scale the distributions of the pressure coefficients were evaluated and the area of the different pressure coefficients calculated. In order to maintain the comparability the same idealized opening of the delivery gates like those for the numerical investigations in Section 2.3 were used. For the joints a general porosity of $0.26 \%$ was considered. The internal pressure was calculated for all six cases as given in Table 1 after Cook's method, [6. The results are listed in Table 3 


\section{RESUlts}

The results of the wind tunnel investigations correspond relatively good to the required values of the Eurocode, for example the Eurocode requires a value of $c_{p e}=2.2$ for the zone $\mathrm{F}$ and the wind tunnel results leads to the highest value of $c_{p e}=2.14$ considering all investigated directions. The results are compared to the $c_{p e, 1}$ values although the area of the measurement points in the experiments correspond to an area of smaller $1 \mathrm{~m}^{2}$ in full scale. The normative values of zone $\mathrm{F}$ and $\mathrm{G}$ suit to the minimum values of the testing results for all directions while the normative value of zone $\mathrm{H}$ fits better to the averaged value. But as one can see in Figure 8 the values of this zone have a certain variation, they decrease in direction to the leeward side of the building. Therefore, it is obvious that a design for the maximum value would not be economic, but one should be aware of the possibility that higher values can occur.

\begin{tabular}{|c|c|c|c|}
\hline Zone & $\mathbf{F}$ & G & $\mathbf{H}$ \\
\hline Eurocode $^{1)}$ & -2.2 & -1.8 & -1.2 \\
\hline $\begin{array}{l}\text { Windtunnel test } \\
\text { (long face) }\end{array}$ & -1.64 & -1.34 & $-1.43\left(-1.19^{2)}\right)$ \\
\hline $\begin{array}{l}\text { Windtunnel test } \\
\text { (all directions) }\end{array}$ & -2.14 & -1.84 & $-1.63\left(-1.29^{2)}\right)$ \\
\hline $\begin{array}{l}\text { Numerical simulation } \\
\text { (Case 1-3) }\end{array}$ & -1.19 & -1.11 & -1.01 \\
\hline $\begin{array}{l}\text { Numercial simulation } \\
\text { (Case 4-6) }\end{array}$ & -1.18 & -1.13 & -1.03 \\
\hline
\end{tabular}

TABle 2. Comparison of the external pressure coefficients $c_{p e}$ for the roof construction.

${ }^{1)} c_{p e, 1}$ values in order to maintain comparability

2) averaged value of zone $H$

The $c_{p e}$ values of the wind tunnel tests for the wind on the long face can be compared to the numerical results of Cases 4 to 6 . It should also be taken into account that the RANS method does not lead to peak values and deliver average value only. The distribution of the external pressure coefficient shows a satisfactory similarity to the experimentally determined distribution from the windtunnel tests. But RANS underestimates the external pressure in the separation area because the turbulence is modelled mathematically and local instationary vortices are neglected. The values of the numerical results are between $72 \%$ to $84 \%$ of the values of the wind tunnel test.

The investigations of the internal pressure coefficients lead to different results for the six cases. The magnitude of the values are similar, in most of the cases, like Case 1, 3 and 6, the Eurocode overestimates the values and is on the safe side, but in Case 5 it underestimates the internal pressure in comparison to the analytical solution.

\begin{tabular}{lcccccc}
\hline Case & $\mathbf{1}$ & $\mathbf{2}$ & $\mathbf{3}$ & $\mathbf{4}$ & $\mathbf{5}$ & $\mathbf{6}$ \\
\hline $\begin{array}{l}\text { Windward } \\
\text { face }\end{array}$ & & short & & & long & \\
\hline Porosity & $\mathrm{X}$ & $\mathrm{X}$ & & $\mathrm{X}$ & $\mathrm{X}$ & \\
\hline $\begin{array}{l}\text { Delivery } \\
\text { gates }\end{array}$ & & $\mathrm{X}$ & $\mathrm{X}$ & & $\mathrm{X}$ & $\mathrm{X}$ \\
\hline Eurocode & -0.30 & 0.34 & 0.64 & -0.03 & -0.33 & -0.83 \\
\hline $\begin{array}{l}\text { Numerical } \\
\text { simulation }\end{array}$ & -0.21 & -0.12 & 0.52 & -0.24 & -0.31 & -0.63 \\
\hline $\begin{array}{l}\text { Analytical } \\
\text { calculation }\end{array}$ & -0.20 & 0.34 & 0.59 & -0.23 & -0.48 & -0.62 \\
\hline
\end{tabular}

TABlE 3. Comparison of the internal pressure coefficients $c_{p i}$ for the six considered load cases.

In Case 2 the numerical analysis lead to a complete different value than the results of the analytical solution, which seems to fit perfectly to the value of the Eurocode. In a further investigation, e.g. with the LES-method, the numerical results should be checked, but it is sure, that this is connected to the position of the opening. If the position of the opening in the analytical calculation is changed to a higher position in the middle of the face (see Fig. 13), the value increases from $c_{p i}=34$ to $c_{p i}=0.45$.

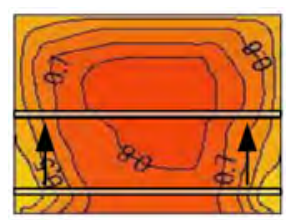

Figure 13. Changed position of the opening at the windward face (TPU Aerodynamic Database 9], modified).

Also in some additional numerical investigations on a $1 \mathrm{~m} \times 1 \mathrm{~m} \times 1 \mathrm{~m}$ cube, where the position of the openings over the height was changed, the same behaviour was determined (see Fig. 14). This shows that the internal pressure reacts quite sensitive to the position of the openings, especially for openings in the windward side.
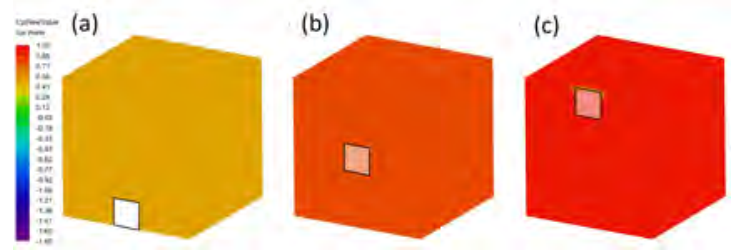

Figure 14. Investigation on a $1 \mathrm{~m} \times 1 \mathrm{~m} \times 1 \mathrm{~m}$ cube due to the position of the opening: (a) Opening at the bottom, (b) opening in the middle and (c) opening at the top.

In Case 4 the Eurocode diagram leads to a value of nearly zero (with $\mu=0.63$ in Fig. 15 in contrast to the numerical and analytical solution, which leads to good corresponding results of -0.24 and -0.23 . In 
the old German code near to zero values were avoided. In the range of the diagram where the value leads to zero one has to consider two values $(0.2$ and -0.3$)$ on the safe side (see the red square in Fig. 15 (b)).

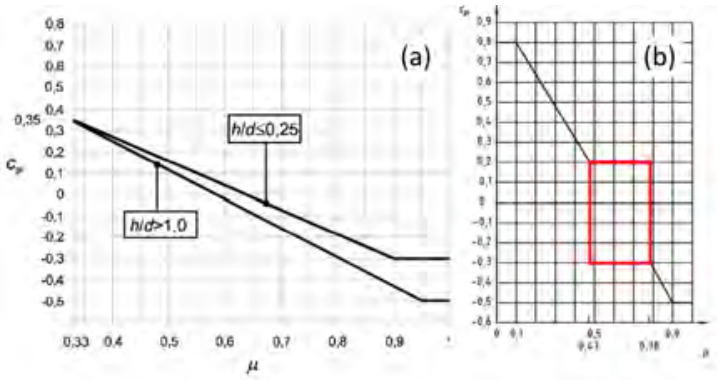

Figure 15. Diagram for the $c_{p i}$ values: (a) Eurocode [1] and (b) the previous code DIN 1055 [10.

\section{Conclusions}

The results show, that the regulation of the internal pressure for a dominant face is conservative for dimensioning a building (see regulation (2.) in Section 2.1). The regulation for homogeneously distributed openings however seems to falsify the internal pressure (see regulation (1.) in Section 2.1). As well for very homogeneously distributed openings, like a general porosity, the Regulation (1.) does not work properly, like in Case 4. Also in Case 5 the value is underestimated in comparison to the analytical value.

The normative DIN EN 1991-1-4 [1] offers the opportunity to use the fixed values of +0.2 and -0.3 , if it is not possible or not justifiable to estimate a $\mu$. These values seems to represent an underestimation of the effects of the internal pressures as one can understand from the results of the investigations for $c_{p} i$ ranging from +0.59 to -0.63 . This apparent load underestimation through the quoted simplified code regulation does not necessarily lead to damages of the structure as it can be assumed to be based on experiences and sound practice requirements which are included into code regulations. However, such configuration can be insecure in connection with a certain systematical underestimation of external pressures after specific design regulation for trapezoidal sheets. For example, the German DIN 18807-3 [11] considers the higher pressures at the edge of the roof (zone F and $\mathrm{G}$ ) just for the design of the screw connections; for the design of the sheets the high suction in these zones is neglected, which leads to an underestimation of the external pressure at the edge of the roof. Together with the simplified Eurocode regulation as described above this can result into a safety relevant lack of net design pressures.

The research on the topic of the internal pressure should be continued to validate the results. To perform some additional wind tunnel tests on buildings with different proportions in combination with numerical simulations would be useful. For the numerical simulations some further methods should be used to improve the results. The aim would be to find a stable model that leads to good results for the different proportions so that it can be used as a tool to check and improve the regulation of the code.

\section{LIST OF SYMBOLS}

$A$ Area of the faces $\left[\mathrm{m}^{2}\right]$

$A^{\prime} \quad$ Area of the openings $\left[\mathrm{m}^{2}\right]$

$c_{p e}$ External pressure coefficient

$c_{p i}$ Internal pressure coefficient

$p_{e} \quad$ External pressure $\left[\mathrm{N} / \mathrm{mm}^{2}\right]$

$p_{i} \quad$ Internal pressure $\left[\mathrm{N} / \mathrm{mm}^{2}\right]$

$w_{e}$ External pressure (Eurocode) $\left[\mathrm{N} / \mathrm{mm}^{2}\right]$

$w_{i}$ Internal pressure (Eurocode) $\left[\mathrm{N} / \mathrm{mm}^{2}\right]$

$\mu$ Opening ratio

$\phi \quad$ General porosity

\section{REFERENCES}

[1] E. C. for Standardization. EN 1991-1-4 - Eurocode 1: Actions on structures - Part 1-4: General actions Wind actions. 2010.

[2] Google Maps. Panoramio, 2007.

[3] Danmark Meteorologiske Institut (DMI). Orkan satte Danmarksrekord i vind - se kortene, 2013.

[4] J. Lange, F. Rädel. Die Fugendichtigkeit von Sandwichelementkonstruktionen - Wasser- und Luftdichtigkeit in Längsfugen und Fensteranschlussfugen. In Festschrift zum 60. Geburtstag von Gerhard Hanswille, Heft 20. Institut für Konstruktiven Ingenieurbau, Bergische Universität Wuppertal, 2011.

[5] M. Kuhnhenne. Energetische Qualität von Gebäudehüllen in Stahl-Sandwichbauweise. Dissertation, Rheinisch-Westfälische Technische Hochschule Aachen, Fakultät für Bauingenieurwesen, 2009.

[6] N. J. Cook. The designer's guide to wind loading of building structures - Part 2: Static structures. Butterworths, 1990.

[7] W.-H. Hucho. Aerodynamik der stumpfen Körper. Vieweg+Teubner, 2nd edn., 2011.

[8] P. Richards, R. Hoxey. Appropriate boundary conditions for computational wind engineering models using the $k-\epsilon$ turbulence model. Journal of Wind Engineering and Industrial Aerodynamics 46-47:145-153, 1993.

[9] T. P. U. Aerodynamic Database. Database of isolated low-rise building without eaves. http://www.wind.arch.t-kougei.ac.jp/info_ center/windpressure/lowrise/mainpage.html.

[10] DIN 1055-4 - Action on structures - Part 4: Wind loads. DIN Deutsches Institut für Normung e.V., 2005.

[11] DIN 18807-3 - Trapezoidal sheeting in buildings; steel trapezoidal sheeting; strength analysis, structural design. DIN Deutsches Institut für Normung e.V., 1987. 